\title{
An Open-Label Study of an Herbal Topical Medication (QoolSkin) for Patients with Chronic Plaque Psoriasis
}

\author{
Arnon D. Cohen ${ }^{1,2}$, Raquel Shalev ${ }^{1,2}$, Ron Yaniv ${ }^{3,4}$, and Avner Shemer ${ }^{3,4}$ \\ ${ }^{1}$ Clalit Health Services and ${ }^{2}$ Siaal Research Center for Family Medicine and Primary \\ Care, Faculty of Health Sciences, Beer-Sheva; ${ }^{3}$ Department of Dermatology, Sheba \\ Medical Center, Tel Hashomer, Israel, Sackler School of Medicine, Tel Aviv \\ University, Tel Aviv and ${ }^{4}$ Maccabbee Health Services, Israel \\ E-mail: arcohen@clalit.org.il
}

Received March 1, 2007; Revised March 24, 2007; Accepted March 25, 2007; Published July 3, 2007

QoolSkin is novel herbal topical medication indicated for the treatment of patients with psoriasis and we endeavored to determine the efficacy of QoolSkin in patients with chronic plaque psoriasis. In an open-label, parallel-group study conducted at four sites in Israel, patients with chronic plaque psoriasis were treated by application of QoolSkin two to three times per day, for a period of 16 weeks. Clinical assessment was performed using the Psoriasis Area and Severity Index (PASI) and the Beer-Sheva Psoriasis Severity Score (BPSS). The study included 100 patients (48 men, 52 women; age 18-65 years). QoolSkin was well tolerated and there were no local or systemic side effects. There was a $19 \%$ reduction in PASI, from a mean of $9.8 \pm 9.5$ before treatment to $8.0 \pm 9.6$ after treatment $(p=0.09)$. There was a $20 \%$ reduction in BPSS, from a mean of $16.1 \pm 9.8$ before treatment to $12.8 \pm 10.6$ after treatment $(p=0.01)$. The reduction in PASI and BPSS was pronounced in women (32 and $31 \%$, respectively) as compared to men ( 9 and $11 \%$, respectively). The reduction in PASI and BPSS was parallel to the length of time the patients were treated by QoolSkin. In patients treated by one of the investigators, who applied QoolSkin three times per day and for a long period of time (mean 101.1 days), the reduction in PASI was $32.0 \%$ and the reduction in BPSS was $37.8 \%$. In patients with chronic plaque psoriasis, QoolSkin treatment was well tolerated. Application of QoolSkin was associated with a decrease in disease severity, as assessed by the patients and physicians. Application of QoolSkin three times per day for long period is associated with a better response to treatment.

KEYWORDS: psoriasis, herbal medication, Israel

\section{INTRODUCTION}

Psoriasis is a chronic disorder characterized by erythematous scaly patches that affect the scalp, trunk, extensor surfaces of the limbs, and the genital area. Psoriasis is highly prevalent in the general population, mainly as a result of its chronicity and the absence of a cure. Patients with psoriasis have high rates of depression and a decreased quality of life. Patients with mild to moderate psoriasis are usually treated 
with topical treatments. Systemic therapy or phototherapy are reserved for patients with moderate to severe disease $[1,2,3,4]$.

Recent studies described the role of complementary and alternative medicine in patients with psoriasis, including mind-body interventions, herbal medicine, nutrition, and traditional Chinese medicine[5,6,7,8,9,10,11,12,13,14,15,16,17,18]. In a recent study by Ben-Arye et al.[19], it was shown that $18 \%$ of Israeli patients with psoriasis used homeopathic medicines.

QoolSkin is an herbal topical medication indicated for the treatment of patients with psoriasis. QoolSkin ingredients include riboflavin, citrus medica limonum (lemon) juice, vinegar, taraxacum oficinalis (danadelion) extract, cereus grandiflorus (cactus) flower extract and opuntia coccinellifera fruit extract, ascorbic acid, calcium ascorbate, sodium ascorbate, and tartaric acid. Uncontrolled observations have shown that QoolSkin is beneficial for patients with psoriasis as reported by patients and complementary medicine personal. However, to date, we have no data on the effect of QoolSkin on psoriasis observed by dermatologists in a planned clinical trial. Therefore, we conducted a clinical trial of QoolSkin in patients with psoriasis. The primary objective of this study was to determine the efficacy of QoolSkin topical treatment in patients with chronic plaque psoriasis.

\section{METHODS}

This was an open-label, parallel-group study to evaluate the tolerability of QoolSkin treatment. The study was conducted at four sites in Israel. Approval for the study was obtained from the Institutional Review Board and written informed consent was obtained from each patient prior to enrollment in the study. The study was conducted in accordance with the ethical principles outlined in the Declaration of Helsinki.

\section{Population}

Patients 18 years of age or older with chronic plaque psoriasis were eligible to participate in this study. Nursing mothers and pregnant women were excluded, as were patients with erythrodermic, pustular, or guttate psoriasis. Exclusion criteria also included patients who had been treated with any systemic antipsoriatic systemic drug within the previous 4 weeks as well as patients with immune suppression.

\section{Treatment}

QoolSkin is an herbal topical medication indicated for the treatment of patients with psoriasis. The complete list of QoolSkin ingredients include water, glycerin, riboflavin, citrus medica limonum (lemon) juice, vinegar, taraxacum oficinalis (danadelion) extract, cereus grandiflorus (cactus) flower extract, opuntia coccinellifera fruit extract, ascorbic acid, calcium ascorbate, sodium ascorbate, and tartaric acid. The patients were instructed to apply QoolSkin formulation on affected skin twice a day (in patients treated by investigators RS, ADC, and RY) or three times per day (investigator AS).

\section{Study Design}

The study was designed as an open-label, parallel-group study conducted at four sites in Israel and included assessments at weeks 2, 4, 8, and 16 after enrollment in the study. It was possible for patient who had a good response to QoolSkin to continue the treatment for a longer time period. 


\section{Efficacy Assessments}

Clinical response was measured using the Psoriasis Area and Severity Index (PASI) and the Beer-Sheva Psoriasis Severity Score (BPSS). The PASI ranges from 0 to 72 and is based on an equation that combines the percentage of affected body surface area (BSA) with an assessment of the extent and severity (erythema, desquamation, and induration) of the psoriatic lesions at four anatomic sites (head, upper extremities, trunk, and lower extremities).

In addition to the PASI, we used the BPSS. This is a novel tool for the ambulatory assessment of patients with psoriasis that has been described by us previously[20]. In the current study, we used BPSS version 2, which has 16 items, 9 of which are recorded by the physician and 7 by the patient, using linear 5- or 6-point visual analogue scales. All scores are summed directly and BPSS ranges from 0 to 71.

An additional objective of this study was an assessment of the tolerability of QoolSkin, which was achieved by assessing local side effects at each visit.

\section{Statistical Analyses}

Safety analyses were carried out on all patients who received QoolSkin. Analyses of efficacy measures were based on the intent-to-treat cohort. Descriptive statistics were used to summarize efficacy endpoints. Results of continuous variables are shown as means \pm SD. To analyze statistically significant differences in continuous parameters before and after treatment, paired t-tests were used. Dichotomous variables were analyzed using chi square tests. Logistic and linear regressions were used for multivariate analyses. $p$ values $\leq 0.05$ were considered statistically significant.

\section{RESULTS}

The study included 100 patients (48 men, 52 women; age $18-65$ years); $36 \%$ of the patients had a positive family history of psoriasis, $24 \%$ of the patients had a history of arthritis or joint pains. The mean length of treatment was 88.1 days (range: 7-253 days). QoolSkin was well tolerated and there were no local or systemic side effects.

There was a $19 \%$ reduction in PASI, from a mean of $9.8 \pm 9.5$ before treatment to $8.0 \pm 9.6$ after treatment $(p=0.09)$. There was a $20 \%$ reduction in BPSS, from a mean of $16.1 \pm 9.8$ before treatment to $12.8 \pm 10.6$ after treatment $(p=0.01)$ (Table 1$)$.

The reduction in PASI and BPSS was pronounced in women (32 and 31\%, respectively) as compared to men ( 9 and 11\%, respectively) (Table 2). The reduction in PASI and BPSS increased with the length of time QoolSkin was applied to the skin (Table 3). The response to QoolSkin treatment was different between the four study sites, according to the treating investigator (Table 4).

The effect of QoolSkin was pronounced in patients treated by one of the investigators (AS). These patients applied QoolSkin three times per day and for a long period of time (101.1 \pm 43.1 days, range 14171 days) (Table 5).

\section{DISCUSSION}

Results of this open-label study show that QoolSkin was well tolerated. At the four study sites, no adverse events were observed. Application of QoolSkin was associated with a decrease in disease severity, as assessed by the patients and physicians. 
TABLE 1

Assessment of Psoriasis Severity Before and After QoolSkin Treatment

\begin{tabular}{|c|c|c|c|c|c|c|c|c|}
\hline & \multicolumn{4}{|c|}{ Before QoolSkin Treatment } & \multicolumn{4}{|c|}{ After QoolSkin Treatment } \\
\hline & Min. & Max. & Mean & SD & Min. & Max. & Mean & SD \\
\hline \multicolumn{9}{|l|}{ Patients' assessment } \\
\hline General assessment & 1 & 5 & 2.8 & 1.3 & 0 & 5 & 2.2 & 1.5 \\
\hline Pruritus & 0 & 5 & 2.4 & 1.6 & 0 & 5 & 1.6 & 1.6 \\
\hline Face involvement & 0 & 5 & 0.5 & 1.0 & 0 & 5 & 0.5 & 1.0 \\
\hline Nails involvement & 0 & 5 & 0.4 & 1.0 & 0 & 5 & 0.4 & 1.0 \\
\hline Palms involvement & 0 & 5 & 0.4 & 1.1 & 0 & 4 & 0.3 & 0.8 \\
\hline Soles involvement & 0 & 5 & 0.4 & 1.1 & 0 & 5 & 0.4 & 1.1 \\
\hline Genital involvement & 0 & 5 & 0.7 & 1.2 & 0 & 5 & 0.5 & 1.1 \\
\hline Patients' total score & 0 & 24 & 7.5 & 5.1 & 0 & 28 & $5.9^{*}$ & 5.6 \\
\hline \multicolumn{9}{|l|}{ Physicians' assessment } \\
\hline General assessment & 0 & 4 & 2.2 & 0.9 & 0 & 4 & 1.8 & 1.0 \\
\hline Scalp involvement & 0 & 4 & 1.1 & 1.3 & 0 & 4 & 0.9 & 1.2 \\
\hline Face involvement & 0 & 4 & 0.4 & 0.8 & 0 & 4 & 0.4 & 0.8 \\
\hline Frontal trunk involvement & 0 & 4 & 0.7 & 1.1 & 0 & 4 & 0.6 & 1.1 \\
\hline Back involvement & 0 & 4 & 0.8 & 1.1 & 0 & 4 & 0.7 & 1.1 \\
\hline Upper limbs involvement & 0 & 4 & 1.6 & 1.0 & 0 & 4 & 1.3 & 1.0 \\
\hline Palms involvement & 0 & 3 & 0.2 & 0.6 & 0 & 3 & 0.2 & 0.6 \\
\hline Lower limbs involvement & 0 & 4 & 1.4 & 1.2 & 0 & 4 & 1.1 & 1.1 \\
\hline Soles involvement & 0 & 3 & 0.2 & 0.7 & 0 & 3 & 0.2 & 0.6 \\
\hline Physicians' total score & 2 & 33 & 8.6 & 5.7 & 0 & 33 & $7.0^{\star \star}$ & 5.9 \\
\hline PASI & 1 & 64 & 9.8 & 9.5 & 0 & 61 & $8.0^{\star \star \star}$ & 9.6 \\
\hline BPSS & 2 & 57 & 16.1 & 9.8 & 0 & 57 & $12.8^{\dagger}$ & 10.6 \\
\hline * $\quad p=0.018$ & & & & & & & & \\
\hline ** $p=0.026$ & & & & & & & & \\
\hline$* * * \quad p=0.090$ & & & & & & & & \\
\hline$\dagger \quad p=0.010$ & & & & & & & & \\
\hline
\end{tabular}

Complementary medicine includes therapeutic modalities that derive from traditional and philosophical systems of medicine, which view health and disease in the context of human totality of body and mind. These practices are perceived as outside of the mainstream domain of medicine[5,6,7,8,9,10,11,12,13,14,15,16,17,18].

QoolSkin is an herbal topical medication indicated for the treatment of patients with psoriasis. QoolSkin ingredients include riboflavin, citrus medica limonum (lemon) juice, vinegar, taraxacum oficinalis (danadelion) extract, cereus grandiflorus (cactus) flower extract and opuntia coccinellifera fruit extract, ascorbic acid, calcium ascorbate, sodium ascorbate, and tartaric acid. 
TABLE 2

Assessment of Psoriasis Severity Before and After QoolSkin Treatment, Stratified by Gender

\begin{tabular}{llllllllll}
\hline & \multicolumn{3}{c}{ Before QoolSkin Treatment } & \multicolumn{3}{c}{ After QoolSkin Treatment } \\
\cline { 2 - 9 } & Min. & Max. & Mean & SD & Min. & Max. & Mean & SD \\
\hline Men & & & & & & & & \\
Patients' total score & 1.0 & 24.0 & 7.9 & 5.4 & 0.0 & 28.0 & 7.2 & 6.4 \\
Physicians' total score & 2.0 & 33.0 & 9.2 & 6.0 & 0.0 & 33.0 & 8.0 & 6.2 \\
PASI & 1.8 & 63.6 & 11.4 & 10.7 & 0.0 & 61.2 & 10.4 & 10.8 \\
BPSS & 3.0 & 57.0 & 17.0 & 10.6 & 0.0 & 57.0 & 15.2 & 11.8 \\
Women & & & & & & & & \\
Patients' total score & 0.0 & 22.0 & 7.0 & 4.8 & 0.0 & 15.0 & 4.4 & 4.2 \\
Physicians' total score & 2.0 & 23.0 & 8.0 & 5.4 & 0.0 & 23.0 & 5.9 & 5.3 \\
PASI & 0.9 & 46.2 & 8.0 & 7.6 & 0.0 & 46.2 & 5.4 & 7.2 \\
BPSS & 2.0 & 35.0 & 15.0 & 8.8 & 0.0 & 34.0 & 10.3 & 8.5 \\
\hline
\end{tabular}

TABLE 3

Assessment of Psoriasis Severity According to the Length of QoolSkin Treatment

\begin{tabular}{cccccc}
\hline & Length of Treatment & $\mathbf{N}$ & Mean & Minimum & Maximum \\
\hline BPSS reduction & $<30$ days & 16 & $0.4 \%$ & $-35.7 \%$ & $58.8 \%$ \\
& $30-60$ days & 15 & $9.7 \%$ & $-80.0 \%$ & $100.0 \%$ \\
& $60-90$ days & 12 & $9.3 \%$ & $-75.0 \%$ & $81.3 \%$ \\
& $90-120$ days & 30 & $26.3 \%$ & $-55.6 \%$ & $100.0 \%$ \\
PASI reduction & $>120$ days & 25 & $51.4 \%$ & $-11.1 \%$ & $100.0 \%$ \\
& $<30$ days & 16 & $3.3 \%$ & $-9.7 \%$ & $40.0 \%$ \\
& $30-60$ days & 15 & $15.7 \%$ & $-7.8 \%$ & $100.0 \%$ \\
& $60-90$ days & 13 & $16.3 \%$ & $-82.8 \%$ & $100.0 \%$ \\
& $90-120$ days & 30 & $23.1 \%$ & $-92.9 \%$ & $100.0 \%$ \\
& $>120$ days & 25 & $48.4 \%$ & $-9.4 \%$ & $100.0 \%$ \\
\hline
\end{tabular}

We observed that the effect of QoolSkin was pronounced after longer periods of application. It is possible that it takes a long time for the herbal ingredients of QoolSkin to effect the skin manifestations of psoriasis, due to the delayed effect on the mind of the patients.

The response to QoolSkin treatment varied according to the treating investigator. As treatment by complementary medicine involves not only the pharmaceutical effects of the medication, but also the attitudes and feelings of the patients, it is possible that the superior effect of QoolSkin observed by one of the investigators (AS) is related to a different approach to complementary medicine of this investigator. Another possible explanation is that the pronounced effect observed in patients treated by AS is related to the fact that these patients applied QoolSkin three times per day and for a longer period of time.

It is possible that the outcomes of QoolSkin treatment observed in the study were attributed to placebo effect or to the lubrication of the QoolSkin formula. However, these preliminary results are encouraging, as the positive effects of herbal treatment were observed concomitantly in four separate research sites. We suggest that a double-blind, placebo-controlled study should be conducted to further assess the efficacy of QoolSkin in patients with psoriasis. 
TABLE 4

Assessment of Psoriasis Severity According to the Treating Investigator

\begin{tabular}{lcccccc}
\hline & Study Site & Investigator & N & Mean & Minimum & Maximum \\
\hline BPSS reduction* $^{*}$ & 1 & RS & 14 & $14.9 \%$ & $-14.3 \%$ & $100.0 \%$ \\
& 2 & ADC & 19 & $3.9 \%$ & $-80.0 \%$ & $81.3 \%$ \\
& 3 & RY & 15 & $11.0 \%$ & $-55.6 \%$ & $82.1 \%$ \\
& 4 & AS & 48 & $37.8 \%$ & $-35.7 \%$ & $100.0 \%$ \\
PASI reduction & 1 & Total & 96 & $23.6 \%$ & $-80.0 \%$ & $100.0 \%$ \\
& 2 & RS & 14 & $27.1 \%$ & $0.0 \%$ & $100.0 \%$ \\
& 3 & ADC & 20 & $12.3 \%$ & $-92.9 \%$ & $100.0 \%$ \\
& 4 & RY & 15 & $11.6 \%$ & $-75.0 \%$ & $97.1 \%$ \\
& 4 & AS & 48 & $32.0 \%$ & $-85.7 \%$ & $100.0 \%$ \\
& & Total & 97 & $24.1 \%$ & $-92.9 \%$ & $100.0 \%$ \\
\hline
\end{tabular}

* $\quad p=0.002$.

TABLE 5

Assessment of Psoriasis Severity Before and After QoolSkin Treatment in 48 Patients Treated by AS

\begin{tabular}{lcccccccc}
\hline & \multicolumn{3}{c}{ Before Treatment } & \multicolumn{5}{c}{ After Treatment } \\
\cline { 2 - 9 } & Min. & Max. & Mean & SD & Min. & Max. & Mean & SD \\
\hline Patients' assessment & & & & & & & & \\
General assessment & 1.0 & 5.0 & 2.6 & 1.3 & 0.0 & 5.0 & 1.5 & 1.1 \\
Pruritus & 0.0 & 5.0 & 2.0 & 1.5 & 0.0 & 4.0 & 0.9 & 1.2 \\
Face involvement & 0.0 & 2.0 & 0.1 & 0.4 & 0.0 & 2.0 & 0.1 & 0.3 \\
Nails involvement & 0.0 & 5.0 & 0.3 & 0.9 & 0.0 & 5.0 & 0.3 & 0.9 \\
Palms involvement & 0.0 & 0.0 & 0.0 & 0.0 & 0.0 & 0.0 & 0.0 & 0.0 \\
Soles involvement & 0.0 & 2.0 & 0.0 & 0.3 & 0.0 & 2.0 & 0.0 & 0.3 \\
Genital involvement & 0.0 & 3.0 & 0.2 & 0.6 & 0.0 & 3.0 & 0.2 & 0.6 \\
Patient total score & 1.0 & 13.0 & 5.2 & 3.1 & 0.0 & 11.0 & 3.0 & 2.7 \\
Physicians' assessment & & & & & & & & \\
General assessment & 0.0 & 4.0 & 2.1 & 0.9 & 0.0 & 4.0 & 1.4 & 1.0 \\
Scalp involvement & 0.0 & 4.0 & 0.9 & 1.3 & 0.0 & 4.0 & 0.7 & 1.1 \\
Face involvement & 0.0 & 2.0 & 0.1 & 0.4 & 0.0 & 2.0 & 0.1 & 0.4 \\
Frontal trunk involvement & 0.0 & 3.0 & 0.4 & 0.9 & 0.0 & 3.0 & 0.3 & 0.7 \\
Back involvement & 0.0 & 3.0 & 0.5 & 0.9 & 0.0 & 3.0 & 0.4 & 0.7 \\
Upper limbs involvement & 0.0 & 3.0 & 1.6 & 0.9 & 0.0 & 3.0 & 1.1 & 0.9 \\
Palms involvement & 0.0 & 1.0 & 0.0 & 0.1 & 0.0 & 1.0 & 0.0 & 0.1 \\
Lower limbs involvement & 0.0 & 4.0 & 1.4 & 1.1 & 0.0 & 3.0 & 1.0 & 0.9 \\
Soles involvement & 0.0 & 1.0 & 0.0 & 0.1 & 0.0 & 1.0 & 0.0 & 0.1 \\
Doctor total score & 2.0 & 21.0 & 7.1 & 4.3 & 0.0 & 21.0 & 5.0 & 4.3 \\
\hline
\end{tabular}




\section{DECLARATION}

The authors have served as investigators for $\mathrm{BMZ}$ as well as other companies that manufacture treatments for psoriasis.

\section{REFERENCES}

1. Ant, M. (1957) Local treatment of psoriasis; including a review of medical literature. Med. Times 85(12), 1397-1402.

2. Mason, J., Mason, A.R., and Cork, M.J. (2002) Topical preparations for the treatment of psoriasis: a systematic review. Br. J. Dermatol. 146(3), 351-364.

3. Farber, E.M. and Nall, L. (1984) Psoriasis. A review of recent advances in treatment. Drugs 28(4), 324-346.

4. Dick, L.A. (1963) Psoriasis--a brief review of treatment in general practice. Skin (Los Angeles) 2, $104-106$.

5. Capella, G.L. and Finzi, A.F. (2003) Complementary therapy for psoriasis. Dermatol. Ther. 16(2), $164-174$.

6. Clark, C.M., Mckay, R.A., Fortune, D.G., and Griffiths, C.E. (1998) Use of alternative treatments by patients with psoriasis. Br. J. Gen. Pract. 48(437), 1873-1874.

7. Fleischer, A.B., Jr., Feldman, S.R., Rapp, S.R., Reboussin, D.M., Exum, M.L., and Clark, A.R. (1996) Alternative therapies commonly used within a population of patients with psoriasis. Cutis 58(3), 216-220.

8. Jensen, P. (1990) [Alternative medicine and chronic skin disease. Use of alternative treatments among patients with atopic eczema and psoriasis]. Tidsskr. Nor. Laegeforen. 110(22), 2869-2872.

9. Jensen, P. (1990) Alternative therapy for atopic dermatitis and psoriasis: patient-reported motivation, information source and effect. Acta Derm. Venereol. 70(5), 425-428.

10. Jensen, P. (1990) Use of alternative medicine by patients with atopic dermatitis and psoriasis. Acta Derm. Venereol. 70(5), 421-424.

11. Kramer, N. (1999) Why I would not recommend complementary or alternative therapies: a physician's perspective. Rheum. Dis. Clin. North Am. 25(4), 833-843, vii.

12. Levin, C. and Maibach, H. (2002) Exploration of "alternative" and "natural" drugs in dermatology. Arch. Dermatol. 138(2), 207-211.

13. Magin, P.J., Adams, J., Heading, G.S., Pond, D.C., and Smith, W. (2006) Complementary and alternative medicine therapies in acne, psoriasis, and atopic eczema: results of a qualitative study of patients' experiences and perceptions. J. Altern. Complement. Med. 12(5), 451-457.

14. McFerren, M.A. (2006) Useful plants of dermatology. VIII. The false hellebore (Veratrum californicum). J. Am. Acad. Dermatol. 54(4), 718-720.

15. Monk, B. (1986) Severe cutaneous reactions to alternative remedies. Br. Med. J. (Clin. Res. Ed.) 293(6548), 665-666.

16. Smith, A.D. (1966) Homeopathy and psoriasis. J. Am. Inst. Homeopathy 59(5), 140-141.

17. Smolle, J. (2003) Homeopathy in dermatology. Dermatol. Ther. 16(2), 93-97.

18. Wiesenauer, M. (1994) [Psoriasis vulgaris. Possibilities and limits of natural healing methods]. Med. Monatsschr. Pharm. 17(3), 78-82.

19. Ben Arye, E., Ziv, M., Frenkel, M., Lavi, I., and Rosenman, D. (2003) Complementary medicine and psoriasis: linking the patient's outlook with evidence-based medicine. Dermatology 207(3), 302-307.

20. Cohen, A.D., Van Dijk, D., Naggan, L., and Vardy, D.A. (2005) Effectiveness of climatotherapy at the Dead Sea for psoriasis vulgaris: a community-oriented study introducing the 'Beer Sheva Psoriasis Severity Score'. J. Dermatolog. Treat. 16(5-6), 308-313.

\section{This article should be cited as follows:}

Cohen, A.D., Shalev, R., Yaniv, R., and Shemer, A. (2007) An open-label study of an herbal topical medication (QoolSkin) for patients with chronic plaque psoriasis. TheScientificWorldJOURNAL: TSW Holistic Health and Medicine 7, 1063-1069. DOI 10.1100/tsw.2007.111. 


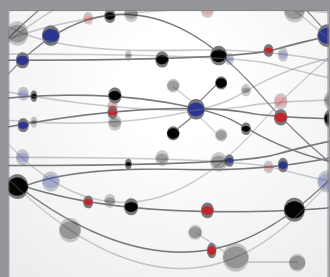

The Scientific World Journal
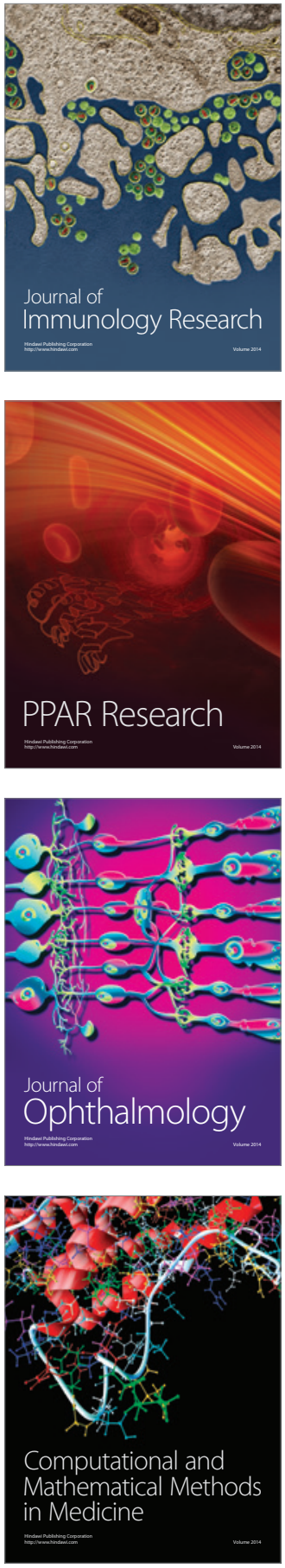

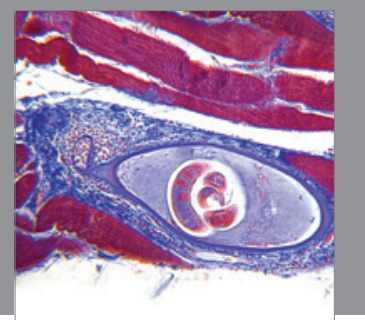

Gastroenterology

Research and Practice
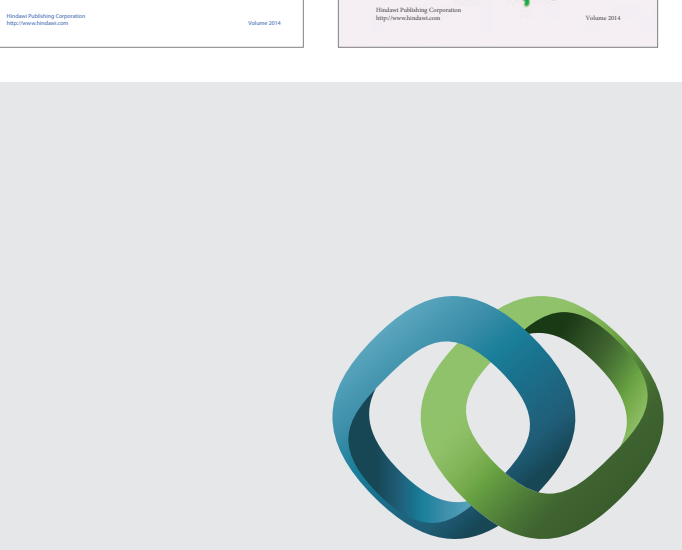

\section{Hindawi}

Submit your manuscripts at

http://www.hindawi.com
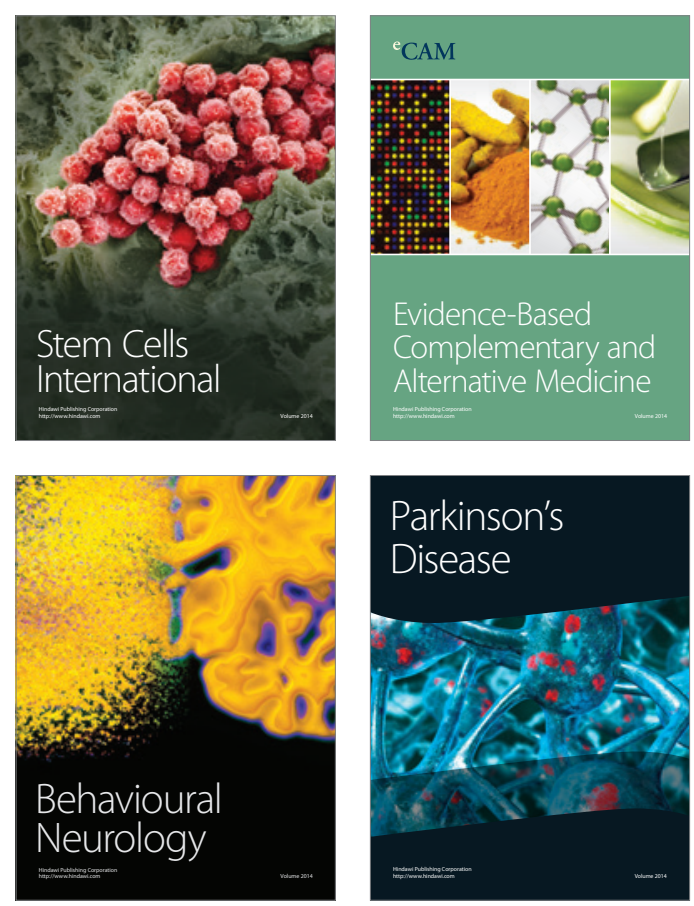

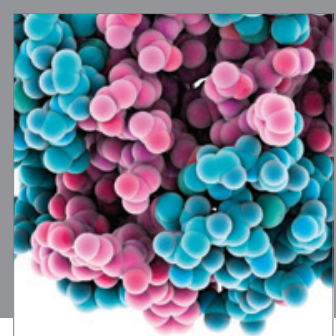

Journal of
Diabetes Research

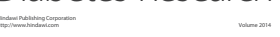

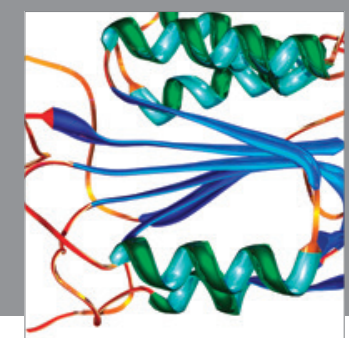

Disease Markers
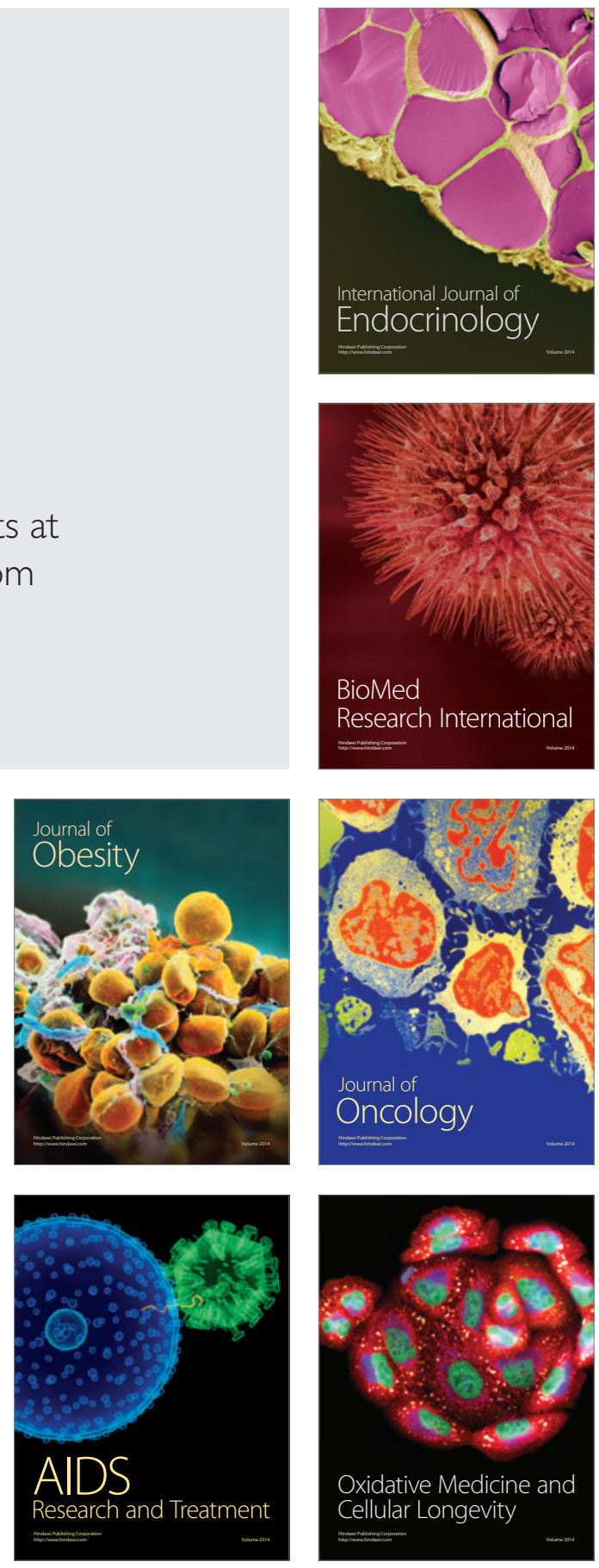